\title{
Why practitioners do (not) apply crisis communication theory in practice
}

\begin{abstract}
Twenty-five in-depth interviews with Belgian crisis communication practitioners were conducted to examine the gap between theory and practice. Crisis communication has become an important research area within public relations. Several studies have resulted in theories and guidelines regarding the effective use of communication during organizational crises. Unfortunately, these findings are not always put into practice. This study examines to what extent public relations practitioners apply theory in practice during crises and why. The findings offer an opportunity to formulate potential ways in which we can bridge the scholar-practitioner divide in public relations, through guidelines for both scholars and practitioners.
\end{abstract}




\section{Why practitioners do (not) apply crisis communication theory in practice}

Crisis communication research has offered a number of clear and useful theoretical guidelines to put into practice. Many of these guidelines stress the accountability of organizations in crisis (cf. Coombs, 2015). Situational Crisis Communication Theory (Coombs, 2007), for instance, indicates that an organization that is blamed for a crisis should communicate crisis response strategies that express acceptance of responsibility. Research on crisis timing strategies similarly stresses the importance of open and responsible communication and shows that organizations should steal thunder (Arpan \& Roskos-Ewoldsen, 2005). That is, they should self-disclose incriminating information instead of trying to conceal it (Claeys \& Cauberghe, 2012). Research illustrates, however, that while offering a full apology might be the most effective crisis response strategy when responsibility attributions are high, the most frequently employed strategies are bolstering and denial (Kim, Avery, \& Lariscy, 2009). In addition, literature suggests that practitioners acknowledge the value of stealing thunder, but rarely selfdisclose crises (Kline, Simunich, \& Weber, 2009; Ulmer, 2012). As such, a gap exists between theoretical guidelines and crisis communication practice. This study aims to explore the roots of this gap to formulate solutions to bridge the divide.

We first discuss potential causes and solutions for the so-called scholar-practitioner divide, or rigor-relevance gap, based on insights from aligned fields (cf. Kieser, Nicolai, \& Seidl, 2015). Then we examine this divide in the context of public relations and, more specifically, crisis communication. A brief overview is given of the most widely supported guidelines in the crisis communication literature. In addition, the few studies that examined the extent of the divide in crisis communication and literature that attempts to bridge it are discussed. Finally, we discuss an exploratory study that conducted 25 in-depth interviews with Belgian communication professionals between February and May 2015. The findings indicate which 
factors limit the practical application of crisis communication theory, according to senior public relations practitioners. These insights allow us to look ahead and explore how we can further stimulate both scholars and practitioners to bridge the "great divide."

\section{Scholar-Practitioner Divide}

The scholar-practitioner divide, or rigor-relevance gap, has been explored in depth in a substantial body of literature in aligned fields such as management science (e.g., Heracleous, 2011; Nicolai, Schulz, \& Göbel, 2011; Kieser et al., 2015). Many authors in the management field have criticized the lack of practical relevance in research (Nicolai et al., 2011). Over the past decades, hundreds of suggestions have been made to close the gap, "yet nothing seems to work, and according to some, the gap continues to grow" (Markides, 2011, p. 121). Two causes have been distinguished (Shapiro, Kirkman, \& Courtney, 2007).

First, a gap exists due to ineffective translation of academic research into publications, frameworks, and tools that practitioners can use. This has been labeled the problem of knowledge transfer, or the "lost in translation" gap. Proposed solutions focus on, for instance, changing editorial policies at academic journals and developing new practicality-oriented journals. Second, a divide between research and practice may be caused not only by the way in which we translate research into practice, but also by the research topics that we select (Shapiro et al., 2007; Markides, 2011). A problem of knowledge production, or a "lost before translation" gap, implies that practically relevant research is not undertaken by academics. This problem may be solved by fostering more collaboration between researchers and practitioners.

Not everyone agrees, however, that scholars should conduct more relevant research or that academic findings should be translated into practice more effectively. Some argue that the relevance problem should not be framed either as a problem of knowledge transfer or as a problem of knowledge production (Rasche \& Behnam, 2009). By doing so, we neglect the 
knowledge "consumer" (i.e., practitioner) who needs to make knowledge relevant in her or his own context of application. Scholars cannot produce relevant knowledge prior to application; practice should make scientific knowledge relevant. A final stance in this debate is that the problem is not so much that research lacks relevance, but rather that the knowledge that is offered is not presented in a form that is useful to our "customers" (i.e., practitioners) (Markides, 2011). Most scientific articles describe very specific findings from one or two studies, much like producing different components of a car (e.g., the steering wheel, tires, etc.). Each of those components is valuable, but useless on their own. We need to convert our research into an assembled product so that its usefulness to practice is clear.

Obviously, the scholar-practitioner divide has been subject to great debate in management science, much more so than in public relations research. Overall, two streams of literature emerge from management science's question with regard to this "great divide" (Kieser et al., 2015): programmatic literature, on the one hand, and descriptive literature, on the other. The programmatic literature receives most research attention and provides opportunities to make academic research more practically relevant. Within the programmatic literature, several streams of thought can be distinguished. Some consider collaborative research as a promising approach to bridge the divide between scholars and practitioners. Although this approach is frequently advocated, it also receives some criticism. Nicolai and colleagues (2011), for instance, examined one specific approach, namely the introduction of joint academicpractitioners' reviewing processes in management journals. Their findings illustrate that the demands of academic and practitioner reviewers may be incompatible and that there can be a striking incongruence between the two groups' ideas of practical relevance. Also, proponents of collaborative research tend to downplay communication difficulties between scholars and practitioners (Kieser \& Leiner, 2012). Critics of collaborative research then argue that collaborative approaches such as action research or consulting should be preferred over actual 
collaborative research. Action research, for instance, proposes that research should address reallife problems and that researchers should participate in problem-solving in practice (Kieser et al., 2015).

Besides the programmatic literature, which offers a wide array of potential solutions to bridge the gap, a second stream of literature consists of descriptive literature, which examines how the results of scientific research are used in practice and discusses the interplay between both (Kieser et al., 2015). Kieser and colleagues (2015) argue that we should move away from the sometimes-uncritical debate on immediate solutions that stems from the programmatic literature and toward a more systematic investigation of how scientific research findings are put into practice. Such an examination can shed light on the relations between research and practice, and serve as a solid basis for evaluating existing suggestions to increase the practical relevance of research and develop new suggestions. That is exactly what the current study aims to do in the context of public relations research and, more specifically, crisis communication.

\section{Scientific Guidelines for Effective Crisis Communication}

In the past few decades, crisis communication has received much research attention within the public relations realm. Two important and widely supported guidelines emerged from this research, namely that organizations should accept responsibility for their mistakes and that they should self-disclose crisis information as early as possible.

Most crisis communication research has focused on the content of an organizational crisis response and more specifically on whether or not organizations should accept responsibility (Avery, Lariscy, Kim, \& Hocke, 2010). The two most influential theories in crisis communication research are Image Repair Theory (IRT) (Benoit, 1995) and Situational Crisis Communication Theory (SCCT) (Coombs, 2007). IRT (Benoit, 1995) offers a list of communication strategies for organizations in crisis and is based on the assumption that crisis 
communication serves the goal of reducing reputational damage. SCCT also offers a list of crisis communication strategies, but adds guidelines on how to match these strategies to different crisis types (Coombs, 2007). Crisis managers should select crisis response strategies that match the amount of potential reputational damage that a certain crisis inflicts, which is determined by attributions of responsibility (Coombs \& Holladay, 2002). Most studies, indeed, indicate that organizations or individuals in crisis should take responsibility and apologize, especially when they are blamed for the events (e.g., Claeys, Cauberghe, \& Vyncke, 2010; Dean, 2004; Lyon \& Cameron, 2004; Sheldon \& Sallot, 2009; Sisco, 2012; Turk, Jin, Stewart, Kim, \& Hipple, 2012; van der Meer \& Verhoeven, 2014). Additional research illustrates that the more an organization explicitly accepts responsibility in an apology, the more positive impressions stakeholders will hold toward that company (Lee, 2005). Therefore, it is not enough to merely apologize. The organization should explicitly announce that it is responsible for the crisis and take responsibility for any misdeeds (Lee \& Chung, 2012).

Communication professionals must also consider the importance of timing during crises. Timing refers to the moment at which information acknowledging that a crisis exists is released (Coombs, 2015). Organizations basically can apply two crisis timing strategies. The first is selfdisclosure and is commonly referred to as stealing thunder, which occurs when an organization "breaks the news about its own crisis before the crisis is discovered by the media or other interested parties" (Arpan \& Roskos-Ewoldsen, 2005, p. 425). The second crisis timing strategy is referred to as thunder and occurs when an organization waits for inquiries from the media or other external sources and responds afterward (Arpan \& Pompper, 2003). Research increasingly has examined whether stealing thunder is indeed beneficial for individuals or organizations in crisis. The findings from this research offer unanimous support for the importance of organizational self-disclosure of crisis information. Stealing thunder results in less media and consumer attention focused on the crisis (Claeys, Cauberghe, \& Pandelaere, 2016; Wigley, 
2011), causes stakeholders to view the crisis as less severe (Arpan \& Roskos-Ewoldsen, 2005), reduces consumers' intention to spread negative information about the organization (Einwiller \& Johar, 2013), and results in a more positive view of the organization and its spokespeople overall (Arpan \& Pompper, 2003; Claeys \& Cauberghe, 2012; Claeys, Cauberghe, \& Leysen, 2013; Fennis \& Stroebe, 2014).

Despite the support for responsibility acceptance and stealing thunder in crisis communication research, communication professionals have conflicting views regarding the appropriateness of this kind of openness in times of crisis (Kline et al., 2009). According to Ulmer (2012, p. 531), "we know that these communication approaches are appropriate yet they rarely are employed during a crisis." The question remains as to whether this assumption is true, and if so, what might explain practitioners' reluctance to apply these strategies.

\section{Crisis Communication Theory in Practice}

A limited amount of research has examined the scholar-practitioner divide in crisis communication. Sisco, Collins, and Zoch (2010) examined the degree to which the actual strategies used by the American Red Cross in response to several crises matched SCCT's guidelines. Their findings illustrate that in practice, the organization used strategies recommended by SCCT only one third of the time. A quantitative content analysis of more than 50 academic articles similarly examined whether or not crisis communicators are practicing what we preach (Kim et al., 2009, p. 446). The findings confirm the gap between public relations theory and practice. The results, for instance, show that denial is the strategy that is used most often in crisis communication practice. The authors conclude that "the prevalence of organizations failing to choose and combine response strategies appropriately in these cases suggests that the bridge between theory and practice may not be as solid as it should be after 18 years of crisis research" (Kim et al., 2009, p. 448). 
These findings indeed offer a discouraging view with regard to the gap between research and practice in public relations. Under the pressure of an actual crisis there can be a tendency to conceal information and deny responsibility (Venette, 2006). To help practitioners avoid such pitfalls and bridge the scholar-practitioner divide, researchers put forward lists of best practices (Janoske, Liu, \& Madden, 2013). Seeger (2006), for instance, formulated a list of 10 best practices in crisis communication based on literature, empirical investigations, and an expert panel. These best practices were updated and validated by Janoske and colleagues (2013) out of explicit concern for the implementation of best practices during crises. According to them, practitioners expressed the need for theory and research to be adequately and actively "translated," so that guidelines can be understood and shared more easily.

Coombs (2015) refrains from using the label "best practices" because this term implies uniformity, and assuming uniformity in crises is misleading. While there can indeed be similarities among crises, "each crisis has the potential to create unique communication demands" (Coombs, 2015, p. 142). Nevertheless, he indicates that prior research in crisis communication provides some consistent results that allow us to formulate overall guidelines regarding strategies that are typically effective or ineffective in times of crisis. Coombs' (2015) effort is in line with Markides' (2011) claim that our research is relevant, but should be converted into an "assembled product" to increase its usefulness to public relations practitioners.

Despite these attempts to bridge the scholar-practitioner divide in crisis communication, few studies have examined the extent of this divide. These studies illustrate that a gap indeed exists, but offer little insight as to what might explain the gap. Without understanding why public relations practitioners refrain from applying theoretical guidelines, it is hard to assess whether efforts, such as best practices, are adequate and what alternative solutions might be. Also, if public relations practitioners do not rely on theory to guide their crisis communication 
practices, it is interesting to know wat is guiding them. Literature about the culture of practitioners suggests, for instance, that public relations professionals rely on a number of truths that are taken for granted (e.g., "build goodwill before you need it"; "talk straight and simple") (Pieczka, 2002, p. 321). To explore the scholar-practitioner divide in crisis communication in depth, our research therefore examines not only if, but also why practitioners in crisis communication fail to put theory into practice:

RQ1. Do crisis communication practitioners put theory into practice?

RQ2. Why do crisis communication practitioners put theory into practice?

RQ3. Why don't crisis communication practitioners put theory into practice?

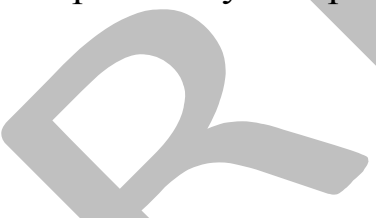

\section{Method}

To answer the research questions above, we opted for in-depth interviews with senior communication practitioners because we wanted to learn more about why crisis communication guidelines are not always put into practice (cf. Rubin \& Rubin, 2005). We aimed to acquire a sample that consisted of companies and organizations from different sectors and of varying sizes. We interviewed both internal communication managers of organizational communication departments $(\mathrm{N}=12)$ and external consultants of well-established public relations consulting firms $(\mathrm{N}=13)$. Participants had an average of 16,9 years of relevant experience, ranging from a minimum of two to a maximum of 35 years of experience. Seven participants received an education in public relations, communication management or communication sciences. Two of them had a degree in journalism studies and five had a background in language studies. Others received a degree in history, multimedia, etc.

The internal communication managers whom we selected work in public-sector organizations (e.g., hospital, educational institution, government) or private-sector 
organizations (e.g., bank, retailer, telecom company). We tried to select respondents from various industries through a purposive sample to increase the generalizability of our findings. Respondents were contacted through mail and asked to participate in the study. As we were interested in authoritative practices, we focused on publicly traded companies, SMEs, and subsidiaries of multinationals located in and around Brussels, capital of the European Union. Only communication managers who had been confronted with crises in the past could participate in the interviews because the study focused on crisis communication experts. One of the participants, for instance, was involved in corporate communications about the CocaCola scare in Belgium in 1999 (cf. Taylor, 2000) and currently works for another well-known multinational company.

From public relations consulting firms, we interviewed senior consultants with a specialty in crisis communication. Both subsidiaries of international public relations companies and independent public relations consulting firms were included in the sample. All firms were wellestablished companies with both national and international clients. Most companies were located in and around Brussels, a region with many multinational organizations that require local consultants for their crisis communication.

Ultimately, 25 communication practitioners were included in the study, 14 of which were female and 11 male. All interviews were conducted face-to-face in the spring of 2015, most on company premises so that the respondents were in familiar surroundings. All interviews were conducted and transcribed in Dutch by a well-trained graduate student. The interviews lasted on average about 46 minutes (range 19-72 minutes) and were recorded using an audio recorder, then transcribed in full. The transcriptions were made in Dutch, and analyses were conducted based on these Dutch transcripts. The quotes that were selected to illustrate the findings were translated to English by a professional translator. Each participant signed an informed-consent form before the start of the interview. The form offered general information about the interview 
topic and explained the procedure. Confidentiality was guaranteed, as participants needed to feel free to discuss sensitive information about crises and how these were handled within their organization or organizations.

The interviews were semi-structured and conducted on the basis of a short topic list with pre-defined questions (cf. Appendix A). The topics were chosen based on several sensitizing concepts (Blumer, 1954) that we took from our literature review. The investigation focused on crisis communication, and more specifically the degree, or lack thereof, to which crisis communication practitioners implement public relations theory into practice. We especially wanted to examine whether practitioners adhere to guidelines from crisis communication literature with regard to the content and timing of crisis communication and for what reasons. Do they recommend that organizations take responsibility for crises, to what degree, and under which circumstances? Do they recommend that organizations steal thunder and why? Finally, we examined whether their stance on these matters is based on academic theory and research or on experience or gut feelings and for what reason.

The interviews were response-driven (Rubin \& Rubin, 2005), each interview contained some structured probe questions and some more spontaneous response driven questions in order to personalize the interviews. As such, the interviews involved close listening and ample space for respondents to expand and digress. During the interviews, the respondents frequently mentioned some theoretical concepts by themselves (as transcribed in some of the quotes). In addition, the interviewer often mentioned and explained some theoretical concepts and theories (e.g., stealing thunder, situational crisis communication theory) to assess the respondents' knowledge, use and perceived added value of these insights during a crisis situation.

All interviews were transcribed verbatim and subjected to a thematic analysis, an accessible and theoretically flexible method for identifying, analyzing, and reporting patterns within data. For this study, we opted for a theoretical thematic analysis, so we focused on aspects across the 
collected data (the transcribed interviews) that had a link with our theoretical interest as described in the literature overview. In other words, we coded for our research question and the corresponding interview items. The coding was done by one of the authors, who is experienced in qualitative research methods. We followed the six phases of thematic analysis as proposed by Braun and Clarke (2006). First, we transcribed and (re-) read the interviews, then we started the coding process by identifying elements in the data that appeared to be interesting in the context of the research question, giving these extracts a specific code (e.g., "gut feeling" and "lack of information available"). In the next phase, we sorted the different codes into potential themes (e.g., "lack of information" was grouped together with other relevant codes into the theme "arguments against stealing thunder"). Once the themes were identified, we re-read the interviews to make sure there was no additional data in the interviews we missed in the earlier coding stage. Next, we identified sub-themes (e.g., we identified within the general theme "arguments against the acceptance of responsibility" three sub-themes, one of them being "immediate responsibility," consisting of all of the coded arguments that made clear why the practitioner may not be conyinced of the need to take immediate responsibility). Finally, we selected some telling extracts to demonstrate the prevalence of the theme(s). By comparing similarities and differences, we identified clusters of practices.

\section{Findings}

Throughout the interviews, it became apparent that each category of participants, both crisis communication experts from public relations consulting agencies and internal communication managers from organizations, had been confronted with crisis situations plenty of times throughout their careers. Most participants were familiar with crises involving restructurings and layoffs, but besides these internal crises, a broad range of situations was discussed by each of the respondents. Most of these events were situated in Belgium, but others 
took place in Europe and beyond. Many examples regarding financial issues were discussed. More specifically, participants mentioned corruption scandals, fraud cases, tax evasion, and organizations' involvement in the 2008 financial crisis. Others discussed crises involving employees, patients, students, or customers victimized by sexual harassment, buildings collapsing, physical aggression, hold-ups in stores, etc. Other crises that came up occurred less frequently, but were no less problematic, such as issues with regard to the radicalization of students at educational institutions. Finally, companies seemed to experience more and more problems with regard to rumors and information leaking through social media.

\section{Do Crisis Communication Practitioners put Theory into Practice?}

The vast majority of communication professionals have studied some course or full program that prepared them for their current jobs. During these sessions, they have seen a lot of theories about public relations in general and crisis communication in particular. However, most respondents said they do not actively use these theories in practice. The most frequently mentioned reason is that the theories are too abstract and that they are not readily applicable by professionals in times of crisis, as the following quotes illustrate:

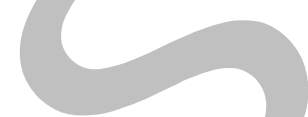

Abstract theories are good for universities and students, but the reality is completely different. In practice, you have to use a very hands-on plan (Respondent 21, consultant).

It is interesting that you have a certain background in your head and that you have knowledge, but those general theories do not know exactly what the company needs, what is appropriate and inappropriate within the company (Respondent 6, communication manager). 
Almost every respondent cited the importance of tailor-made guidelines. The communication professionals have a general communication plan that they then adjust to specific cases. They rely mainly on gut feelings as the most important factor to implement the communication plan. Whether or not participants had an educational background in public relations did not seem to affect their application of theory in practice. Participants that had a degree in public relations, like the other participants, indicated that theories look good on paper but that they mainly rely on gut feelings and experience when responding to a crisis. Nevertheless, several respondents clarified that their practices are based on more than just that gut feeling and that their intuition is rooted in previous experiences and scientific research that serve as a general basis for their communication plans. One respondent (23, consultant) argues that "it is rationalized gut feeling, knowing what to do based on your experience", while another says that at their organization they "rely on experience combined with knowledge of theories. We call it 'solidified experience'. It is a kind of intuition that is based on knowledge, both practical and theoretical knowledge" (respondent 14, consultant).

As an answer to the first research question, we can conclude that public relations professionals generally indicate that they rely mainly on experience and gut feelings, rather than specific theories. When discussing their actual behavior during past crises, however, the findings indicate that they understand the basic premises made by theories, but that they take a number of factors into consideration when putting theoretical guidelines into practice. We first discuss the reasons practitioners cite for communicating responsibly and transparently, in order to find an answer to the second research question and explain why crisis communication professionals use theoretical guidelines in practice. We then discuss why practitioners tend to apply these theoretical guidelines only in their own specific ways and under specific 
circumstances, in order to explain why practitioners sometimes choose not to apply theoretical guidelines and formulate an answer to the third and final research question.

\section{Why Do Practitioners Apply Theory to Their Practice?}

The interviews present a general picture of communication practitioners who are prepared to take responsibility for their organization's actions. In addition, all 25 respondents accepted the value of stealing thunder, in theory. However, many had differing views on whether or not to implement such a strategy automatically. We first explore why practitioners agree that organizations in crisis should communicate both responsibly and transparently.

Belgian public relations practitioners see the overall willingness of organizations in crisis to take responsibility as a positive evolution and link it to a number of guiding principles, such as communicating transparently and showing empathy. The interviews reveal three main reasons for this. First, there is a view that no other course is viable in modern times; it is no longer possible to truly conceal something. Journalists relentlessly will seek the truth, and a continual flurry of exposés will eventually compel a disclosure. The second reason centers on the positive impact on the business, even in a crisis situation. Negative news can be presented in a positive manner to reflect favorably on the corporate image. One respondent referred to a crisis situation as a "moment of truth" that allows a company to reveal its inner character. The final reason given was that taking responsibility can add a human element to the situation; the public is aware that things can go wrong and can empathize with a company that does not try to hide this. Or as the following quote illustrates:

Sometimes companies do get things wrong and, when that happens, I think people will find you more credible if you're willing to be honest about it. The focus needs to be on minimizing the damage and developing a plan to make sure it doesn't happen again. 
But if all you want to do is conceal the truth, I don't think anyone will appreciate that (Respondent 1, communication manager).

Everyone agreed that pushing the blame onto others is not a good communication strategy. Companies remain responsible for their sub-contractors, staff, and suppliers, and those who do not actively address their partners' failings risk being dragged down with them.

As regards the timing of communication, there was a far greater division of opinion compared with the previous issue. Some of the respondents were very much in favor of stealing thunder, supporters of which cited three reasons. The first is the need for rapid communication during crisis situations. They say a slow response may further exacerbate the issue. There is the concept of the "golden hour" - the first hour after the scandal breaks - which is said to be crucial for communication. A rapid response can reflect favorably on the corporate image. The second and principal reason given by respondents, however, was that the original communicator has more control over the subsequent narrative (its content, tone, and timing). Missing this opportunity may lead to other parties claiming ownership of the issue, along with its narrative. This may limit the company to merely reactive measures, or even defensive communication, which, according to the practitioners, should be avoided at all costs. Respondent 15 (consultant) for example argues that "our advice is (...) to respond proactively in order to avoid a news cycle where you're constantly firefighting the release of new facts, which sends an implicit message that you have something to hide". The same goes for respondent 2 (communication manager) who also refers to social media: "It's better to communicate proactively than to wait until you're already cornered. Trying to correct information that's already been put out by the media is incredibly difficult. People have already begun to form opinions, and the advent of the Internet and social media has only accelerated this." 
The final reason mentioned for the need to communicate proactively was the simple principle that "the truth will get out." A number of practitioners linked this to the negative consequences of the emergence of news that a company had attempted to conceal:

Experience has shown that you may as well steal thunder because people will find out anyway. I think I've seen this in every book I've read on strategic communication as well: It's better to clean up your own mess. If you cover it up, you're taking the risk that it could rebound on you - and if it does, everyone will say you knew all along but never fixed it (Respondent 3, communication manager).

One practitioner (respondent 15) - who happened to be a former journalist - explicitly linked the stealing thunder strategy to the world of journalism. Proactive communication makes a story less interesting for journalists because they can no longer claim an exclusive scoop: “ $A$ proactive response takes the wind right out of a journalist's sails. It means they'll be far less keen to take a sensationalist angle. I think journalists soon learn to tell when a company is prepared for a crisis and when it isn't, and whether it's got everything under control. If it has (...) there's not much more the journalist can say."

\section{Why Don't They?}

Clearly then, there are several reasons to employ the stealing thunder strategy. Nevertheless, analysis of the interviews also reveals a number of arguments offered by opponents against the automatic assumption of such a proactive stance. In addition, while all respondents supported the need to take responsibility in times of crisis, many of them appear to do so only in specific ways or under specific circumstances. Overall, participants offer three very similar reasons why organizations tend not to take responsibility or to not self-disclose 
incriminating information. First, organizations have a tendency to wait as long as possible before they implement any of these strategies, which is contradictory to their very essence. Second, they only will accept responsibility and steal thunder under limited circumstances. Third, public relations practitioners take management and legal implications under consideration.

Not immediately. Not every practitioner is convinced of the need to take immediate responsibility. One common problem is that, at the moment of outbreak, there is often very little information available about the nature of the problem and who might be responsible. This means a public relations practitioner may well end up providing incorrect information that must subsequently be corrected when further details come to light. This is considered a transgression of good communication principles.

With regard to the self-disclosure of incriminating information, various practitioners also noted that there is often insufficient information available to give the public a clear picture of events, in which case organizations prefer to remain silent rather than risk giving out incorrect information. After all, the accuracy of communication is also vital:

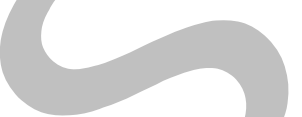

Proactive communication is a good thing, but it does depend on the situation. (...) It's still essential that everything you say is true, so giving out information for the sake of it is a bad idea. When in doubt, or when there's a huge crisis that we don't yet know much about, it's not opportune. (...) Never say anything if you don't know it's true or if it might later be proven false (Respondent 17, consultant).

Others also acknowledge this problem, although some would add that a total lack of communication is just as undesirable and that proactive communication is still possible, even 
without all of the facts at one's fingertips. This relates to the approach of exercising suitable control over the organization's communication.

Nevertheless, the prevailing approach seems to be to resolve a crisis internally in the hope that it never reaches the public square. The interviews do reveal that practitioners are perfectly aware of the risks involved in doing so, and that a rapid response remains the best course of action if the issue is ultimately reported externally. A number of practitioners made explicit mention of a strategy to await developments while actively monitoring and attempting to anticipate a sudden revelation:

It's important to wait and see. Monitor! Check if it turns up in the press first and only respond once it does. But also be prepared-internally draft a statement suggesting that the company is aware of the issue and is taking steps to address it ... you can then use it the moment it appears in the press or someone mentions it on social media. So a statement may well be prepared in advance, just in case, but not necessarily used. If we can 'keep it in the family, 'that's where it ought to stay (Respondent 18, consultant).

Not under all circumstances. Not every practitioner is convinced of the need to take responsibility or steal thunder in every situation. With regard to the necessity of accepting responsibility, some respondents say it depends, and may vary from case to case. In addition, some practitioners refrain from responsibility acceptance because they fear that it equals admitting that the company was at fault. Others understand this fear, but suggest that they believe organizations can apply this strategy regardless, when they do so in a specific manner. They suggest that it is perfectly possible for a company to show empathy and investigate ways of resolving the crisis without giving the impression that the organization has caused it, or as respondent 13 argues: “Companies are often quite happy to take responsible actions as long as 
this isn't seen as an admission of guilt - that's the difference. They're perfectly willing to take responsibility for resolving the crisis, but admitting they're effectively responsible for causing it is another matter entirely."

With regard to stealing thunder, practitioner interviews clearly demonstrate that the decision as to whether or not to communicate proactively depends on the nature of the issue at hand. They refer both to the extent of the crisis ("there's no sense crying over spilt milk") and to whether the issue is largely internal in nature. If so, there is a clear preference among the experts for resolving the matter internally and, thereby, letting sleeping dogs lie:

If you know for sure it's going to get out, you may as well be the first to mention it. But if you can resolve it without anyone coming to harm, then it's best to let sleeping dogs lie. Say we noticed something was amiss with a product, but it hadn't hit the stores yet - why would we tell the whole world (Respondent 4, communication manager)?

It depends on the situation. If the crisis involves harm or damage and ought to be public knowledge, then you'll have to own up. If it's not on that scale, though, I can't imagine we'd make too much of a fuss. If someone did bring it to light later on, we'd communicate at that stage (Respondent 1, communication manager).

Communication is not the only factor at play. The interviews lastly reveal that the decisions made by public relations practitioners do not occur in a vacuum. Respondents indicate that they take legal issues into consideration when making their decisions and also experience difficulties when trying to convince management of certain strategies.

Both of the arguments that were raised against accepting responsibility, namely the fear of doing so too early or of giving the impression that the company was at fault, are linked to 
potential legal implications. First, a company claiming responsibility at an early stage may well find itself in an unfavorable position when legal liability is determined, even if it is later revealed that it could not have been responsible. This reasoning can often prevent a practitioner from claiming responsibility at the earliest opportunity. Second, practitioners, according to whom taking responsibility might give the impression that the company were to blame, fear that taking responsibility equals admitting liability.

With regard to the general stance of practitioners toward legal considerations, an interesting finding emerged from the interviews with the external public relations consultants: About half of these respondents indicate that they are often in conflict with the legal departments of the companies they represent. According to these respondents, communication experts and lawyers have conflicting interests, and the legal department is often afraid to communicate transparently about a crisis. The consultants indicate that they often try to convince the legal experts of the need to communicate in an open manner:

Communication experts want to communicate. Legal advisers usually argue that what you're saying now will be used against you two years later in court. We reply that by that time, the company probably will not exist anymore (Respondent 22, consultant).

The other half of the public relations consultants sees value in consulting with legal experts, an opinion shared by all internal communication managers interviewed in this study. They see great value in cooperation and consultation between the communication and legal experts because communication professionals are often not very aware of the legal specificities of a particular case. Rather than convincing the legal practitioners of the need for transparent communication without taking into account the legal aspects, they usually look for a compromise. Respondent 16 for example does not see the intervention of a legal expert as an 
obstacle: "I find it useful to know their opinion and advice because sometimes, it involves a lot of money. I think it's important to collaborate, instead of just acting from your own experience as a communication expert." Another communication expert argues that "sometimes we clash because everyone thinks from their own point of view. We think about image, image, image while they worry about the steps to be followed from a legal standpoint. But we always try to reach a compromise” (respondent 6, communication manager).

Besides legal implications, respondents discussed the difficulties of convincing management of certain strategies, especially stealing thunder. Management often hopes that an issue will never be brought to light, or simply cannot reconcile the approach with their own particular situation. The interviews with external consultants, in particular, show that it can be very difficult to persuade a company to apply the stealing thunder strategy effectively, as the following quote illustrates:

It isn't always easy to convince a company. We can produce all kinds of examples where the stealing thunder approach proved its worth, but then they often say, 'yes, that might have worked there, but we're in a different position' (Respondent 14, consultant).

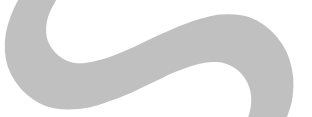

Implications of the reservations made by practitioners. These findings help formulate an answer to the third research question and as such indicate why crisis communication professionals do not always put theory into practice. Practitioners are willing to accept responsibility and self-disclose crisis information, but not immediately, not under all circumstances, and they need to take legal liability and restraints from management into consideration. These reservations made by practitioners can have serious implications for the outcomes of their crisis communication efforts. As a result, they may hold back on taking responsibility for so long that the public and media already will have convicted the company. 
And by waiting until the first rumors about a crisis pop up on social media before disclosing the events, the whole advantage of stealing thunder will have long passed.

In addition, practitioners prefer to apologize in a way that does not imply that the organization is actually at fault. In other words, they want to apologize in a way that indeed reduces legal liability but that, according to research (cf. Lee, 2005; Lee \& Chung, 2012), will not effectively minimize reputational damage. Similarly, crisis information can be disclosed, but only if the crisis has a large impact and is external, i.e., only when it is inevitable that the crisis will be publicized soon by a third party.

With regard to the fear of legal implications amongst practitioners, we contacted two Belgian crisis communication professionals ${ }^{1}$ after analyses of the interviews and asked to what degree legal regulations differ between Belgium and the U.S. and how any such differences may have affected the findings. Without going into the specifics of each country's laws and regulations, each of them indicated that the fear of legal consequences is likely to be an even more important factor for public relations practitioners in the U.S. than those in Belgium. However, due to the recent introduction of class actions in Belgium and other European countries (cf. Catteau \& Willems, 2014), Belgian organizations may consider the legal consequences of their crisis communication far more closely than in the past. Therefore, legal consequences can complicate the practical application of crisis communication theory in Europe, the U.S., and elsewhere.

\section{Implications}

The findings from this study first indicate whether or not practitioners claim to know, understand, and apply theory in practice. Most respondents indicate that they find most theories

\footnotetext{
${ }^{1}$ We contacted one male senior public relations consultant who had participated in the study and one female senior public relations consultant who had not participated in the study through e-mail. Both work for different companies in Brussels, each of which specializes in crisis communication.
} 
too abstract and difficult to translate to actual crisis situations with which they are confronted. These findings quite literally point to the existence of a "lost in translation" gap (cf. Shapiro et al., 2007) or a problem of knowledge transfer (cf. Rasche \& Behnam, 2009). Most practitioners claim to rely on their gut feeling when communicating in times of crisis and developing communication plans. They do, however, acknowledge that this gut feeling is rooted in not only their professional experience, but also in their theoretical background. This observation is confirmed when practitioners are asked about their actual response to certain crisis situations. Overall, practitioners do appear to support general theoretical guidelines and seem willing to apply them in practice. Nevertheless, it appears from our findings that a gap remains when we consider the way in which practitioners apply these guidelines and when. The main aim of this study was to examine what both research and practice can do to overcome this gap. We addressed this question by first examining how academics can resolve issues with regard to knowledge transfer and knowledge production. We then continued by also taking into consideration how the knowledge "consumer", that is public relations practitioners, can help in bridging the divide.

\section{What Can Scholars Do to Bridge the Gap?}

Even though research repeatedly has shown that organizations should accept responsibility and how, practitioners do not put this strategy into practice in the most effective manner. Even though theories such as SCCT (Coombs, 2007) offer a framework with clear guidelines for practitioners, professionals complain that theories do not always correspond with practical needs. Even though academics formulate best practices (cf. Janoske et al., 2013; Seeger, 2006), practitioners call for more "tailor-made" guidelines. It seems safe to assume that despite our efforts, public relations research indeed gets lost in translation (cf. Shapiro et al., 2007). 
Therefore, we should not only make relevant knowledge available to practitioners, but also find ways to bring that knowledge to them and work with them to apply it in practice.

Janoske et al. (2013) suggest that translational work can be established by organizing workshops that bring academics and practitioners together. In addition, we should organize and attend conferences that target both academics and practitioners (e.g., conferences hosted by the European Public Relations Education and Research Association or the Public Relations Society of America). Management research further indicates that besides workshops, we could focus on training, publication outlets, and incentives that help academics translate their research (Shapiro et al., 2007).

Besides the translation of theories into practice, the gap might also be reduced by efforts to promote open access to academic publications. Nowadays, we should finally go beyond these more traditional research outlets and bridge the gap through social media. We know that public relations practitioners are active on social media (cf. Diga \& Kelleher, 2009). Therefore, we should communicate our findings not only through conferences and academic journals, but through blogs as well. Researchers could also discuss actual crisis situations in a vlog that would allow them to link these cases to theories in an accessible way. In addition, we can tweet about our most important findings or provide web links to our full papers via Twitter.

Besides this problem of knowledge transfer, we should further tackle the problem of knowledge production. How do we increase collaboration between researchers and practitioners? Collaborative research has received criticism because there may be communication difficulties between scholars and practitioners (Kieser \& Leiner, 2012). Inviting both academics and practitioners to review journal articles, for instance, appears to be difficult because both parties seem to have different ideas about what practical relevance means (Nicolai et al., 2011). Nevertheless, other collaborative approaches might be interesting. Shapiro et al. (2007) suggest practitioner sabbaticals that would allow public relations 
professionals to help translate research results or participate in research. Another option would be to foster more researcher-practitioner collaboration through specific research programs. In Belgium, for instance, the Research Foundation-Flanders offers doctoral grants for strategic basic research, with the aim of conducting innovative research that leads to applications with added value for specific companies and sectors.

Solutions for the problem of knowledge production also can be initiated by studies like these, which bring to the surface specific problems that practitioners face. Such studies can form the starting point for new research ideas that appeal to practitioners. The findings of our study show, for instance, that practitioners fear the legal consequences of responsibility acceptance. Therefore, more research is needed to examine the actual legal consequences of apologies and responsibility acceptance. A recent study illustrates that in many U.S. jurisdictions, apologies are not admitted into evidence if the apology contains certain characteristics (Myers, 2016). Yet, this study advises avoiding litigation by apologizing in such a way that the organization avoids admitting guilt, a recommendation that contradicts the finding that an effective apology in terms of reputation repair should explicitly announce that the organization is responsible (Lee \& Chung, 2012). Thus, more research is needed to examine the long-term costs of an apology versus denial, both for those organizations that turn out to be guilty and those that are not. A rare and interesting experimental study that examined the legal implications of apologies, for instance, indicates that apologies can facilitate legal settlements (Robbennolt, 2006). Much more research about the legal and financial costs related to crisiscommunication strategies would, however, benefit practitioners.

Finally, the findings indicate that practitioners have difficulties convincing management that certain theoretically sound strategies are a good way to go. Hence, we should examine ways in which practitioners can convince management to embrace open and transparent communication. We could, for instance, broaden our scope and focus on transferring our 
knowledge not only to public relations practitioners, but also directly to management. One way of doing so is simply by publishing crisis communication research findings not only in public relations-related journals, but also in business journals (e.g., Coombs, 2015; Claeys et al., 2016).

\section{What Can Practitioners Do to Bridge the Gap?}

Debates about the scholar-practitioner divide usually focus on what academics can do to bridge the gap, yet "the relevance debate can profit from a more balanced perspective that equally considers the roles of knowledge producers and consumers" (Rasche \& Behnam, 2009, p. 252). Therefore, we should consider what public relations practitioners can do to increase the application of theoretical findings in practice. Many of the recommendations described earlier apply to both scholars and practitioners. When practitioners organize conferences or publish blogs, they should invite contributions from scholars. Also, practitioners should keep abreast of the latest academic findings through further education or research publications. Research interest in crisis communication has significantly increased over the past few decades (cf. Kim et al., 2009), so insights nowadays are different from the ones that senior practitioners might have learned years ago. This also may partly explain the findings in this study because all participants were senior public relations professionals.

Finally, participants in the study said the theories and frameworks offered by scholars are too abstract, and they want more tailor-made guidelines. However, the idea of theories and frameworks such as SCCT is that they offer principles that can be applied to very specific circumstances. Thus, practitioners should get more thoroughly acquainted with these theories through workshops, seminars, etc., so that they can learn how to apply each theory in practice.

By means of these suggestions we aim to move the discussion about the scholarpractitioner divide in crisis communication away from one-sided approaches that examine 
either whether practitioners apply theories in practice or how scholars can translate research to practice. The information that we retrieved from crisis communication experts allowed us to formulate specific suggestions that can bridge the divide between theory and practice in crisis communication and in public relations overall.

\section{Limitations and Further Research}

This study examined whether or not crisis communication professionals put theory into practice and why. Based on the findings from our study and prior research, we offer some suggestions about what both scholars and practitioners can do to bridge the scholar-practitioner divide. However, further research should take the opportunity to ask practitioners in what ways they might possibly be more open to and seek out research. Also, interesting insights in this regard could be derived not only from aligned fields such as management studies, but from more applied disciplines (e.g., medicine/public health) as well.

The findings from this study are based on the views and experiences of crisis communication professionals in Belgium. As such, the findings may lack generalizability. Nevertheless, we believe that the sample draws an interesting and relevant picture of crisis communication practices for all communication scholars and professionals for two main reasons. First, respondents were selected to represent a broad range of companies and sectors. Both external consultants of public relations consulting firms and internal communication managers from organizations were interviewed. This resulted in a large diversity of respondents that provide interesting insight into the field. Second, many of these practitioners are employed in Brussels, the capital of Europe. This location implies that the consulting firms have great experience with crisis communication for large multinationals. These multinationals greatly depend on local public relations companies, especially in times of crisis. Similarly, many of the 
interviewed communication managers work for subsidiaries of large multinationals for which crises are an important reality.

Nevertheless, it would be interesting to compare these findings to the experiences of communication professionals from different countries to take into account potential crosscultural variations (cf. Claeys \& Schwartz, 2016). Cross-cultural research could expose country-specific differences in legal systems or laws, as well as their effects on the scholarpractitioner divide. Besides legal differences, other cultural considerations should be taken into regard as well. While such differences did not come up during the interviews, one of the communication professionals that we contacted after the analyses, to ask about legal differences between Belgium and the U.S., also brought up potential cultural differences. He suggested that the public in the U.S. might be more open to apologies by CEO's in times of crisis than European consumers. Also, corporate failure might be considered more acceptable in the U.S. than in Europe, which could affect European CEO's willingness to admit mistakes. These potential cultural differences receive support from a cross-cultural analysis of image repair strategies applied by former President of the United States Bill Clinton and former Prime Minister of Italy Silvio Berlusconi (Garcia, 2011). While Clinton eventually apologized for his misbehavior, Berlusconi consistently denied charges and attacked his accusers. Nevertheless, both responses seemed appropriate in their own cultural context.

In conclusion, this study hopes to offer a starting point for more research to increase our insights into the scholar-practitioner divide, and more importantly, to provide effective solutions.

\section{References}


Arpan, L.M., \& Pompper, D. (2003). Stormy weather: testing "stealing thunder" as a crisis communication strategy to improve communication flow between organizations and journalists. Public Relations Review, 29(3), 291-308.

Arpan, L.M., \& Roskos-Ewoldsen, D.R. (2005). Stealing thunder: Analysis of the effects of proactive disclosure of crisis information. Public Relations Review, 31(3), 425-433.

Avery, E.J., Lariscy, R.W., Kim, S., \& Hocke, T. (2010). A quantitative review of crisis communication research in public relations from 1991 to 2009. Public Relations Review, $36(2), 190-192$.

Benoit, W.L. (1995). Accounts, excuses, and apologies: A theory of image restoration strategies. Albany: State University of New York Press.

Blumer, H. (1954). What is wrong with social theory? American Sociological Review 19(1), $3-10$.

Braun, V., \& Clarke, V. (2006). Using thematic analysis in psychology. Qualitative Research in Psychology, 3(2), 77-101.

Catteau, A., \& Willems, J. (2014, May 12). “Class Actions” worden realiteit in België ["Class Actions" become a reality in Belgium]. Retrieved from http://www.lexgo.be/nl/artikels/gerechtelijk-recht/burgelijke-procedure/iclass-actionsi-

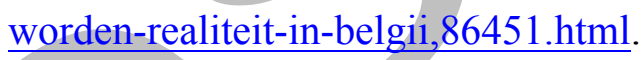

Claeys, A.-S., \& Cauberghe, V. (2012). Crisis response and crisis timing strategies, two sides of the same coin. Public Relations Review, 38(1), 83-88.

Claeys, A.-S., Cauberghe, V., \& Leysen, J. (2013). Implications of stealing thunder for the impact of expressing emotions in organizational crisis communication. Journal of Applied Communication Research, 41(3), 293-308. 
Claeys, A.-S., Cauberghe, V., \& Pandelaere, M. (2016). Is old news no news? The impact of self-disclosure by organizations in crisis. Journal of Business Research, 69(10), 39633970

Claeys, A.-S., Cauberghe, V., \& Vyncke, P. (2010). Restoring reputations in times of crisis: An experimental study of the Situational Crisis Communication Theory and the moderating effects of locus of control. Public Relations Review, 36(3), 256-262.

Claeys, A.-S., Schwarz, A. (2016). Domestic and international audiences of organizational crisis communication: State of the art and implications for cross-cultural crisis communication. In: Schwarz A., Seeger M., Auer C. (Eds.), The Handbook of International Crisis Communication Research Wiley-Blackwell, 224-235.

Coombs, W.T. (2007). Protecting organization reputations during a crisis: The development and application of situational crisis communication theory. Corporate Reputation Review, 10(3), 163-176.

Coombs, W.T. (2015). The value of communication during a crisis: Insights from strategic communication research. Business Horizons, 58(2), 141-148.

Coombs, W.T., \& Holladay, S.J. (2002). Helping crisis managers protect reputational assets: Initial tests of the situational crisis communication theory. Management Communication Quarterly, 16(2), 165-186.

Dean, D. H. (2004). Consumer reaction to negative publicity: Effects of corporate reputation, response, and responsibility for a crisis event. Journal of Business Communication, $41(2), 192-211$.

Diga, M., \& Kelleher, T. (2009). Social media use, perceptions of decision-making power, and public relations roles. Public Relations Review, 35(4), 440-442. 
Einwiller, S.A., \& Johar, G.V. (2013). Countering accusations with inoculation: The moderating role of consumer-company identification. Public Relations Review, 39(3), 198-206.

Fennis, B.M., \& Stroebe, W. (2014). Softening the blow: Company self-disclosure of negative information lessens damaging effects on consumer judgment and decision making. Journal of Business Ethics, 120(1), 109-120.

Garcia, C. (2011). Sex scandals: A cross-cultural analysis of image repair strategies in the cases of Bill Clinton and Silvio Berlusconi. Public Relations Review, 37(3), p. 292-296.

Heracleous, L. (2011). Introduction to the special issue on bridging the scholar-practitioner divide. The Journal of Applied Behavioral Science, 47(1), 5-7.

Janoske, M.L., Liu, B.F., \& Madden, S. (2013). Congress report: Experts' recommendations on enacting best practices in risk and crisis communication. Journal of Contingencies and Crisis Management, 21(4), 231-235.

Kieser, A., \& Leiner, L. (2012). Collaborate with practitioners: But beware of collaborative research. Journal of Management Inquiry, 21(1), 14-28.

Kieser, A., Nicolai, A., \& Seidl, D. (2015). The practical relevance of management research: Turning the debate on relevance into a rigorous scientific research program. The Academy of Management Annals, 9(1), 143-233.

Kim, S., Avery, E.J., \& Lariscy, R.W. (2009). Are crisis communicators practicing what we preach? An evaluation of crisis response strategy analysed in public relations research from 1991 to 2009. Public Relations Review, 35(4), 446-448.

Kline, S.L., Simunich, \& Weber, H. (2009). The use of equivocal messages in responding to corporate challenges. Journal of Applied Communication Research, 37(1), 40-58.

Lee, B.K. (2005). Hong Kong Consumers' evaluation in an airline crash: A path model analysis. Journal of Public Relations Research, 17(4), 363-391. 
Lee, S., \& Chung, S. (2012). Corporate apology and crisis communication: The effect of responsibility admittance and sympathetic expression on public's anger relief. Public Relations Review, 38(5), 932-934.

Lyon, L., \& Cameron, G.T. (2004). A relational approach examining the interplay of prior reputation and immediate response to a crisis. Journal of Public Relations Research, $16(3), 213-241$.

Markides, C. (2011). Crossing the chasm: How to convert relevant research into managerially useful research. The Journal of Applied Behavioral Science, 47(1), 121-134.

Myers, C. (2016). Apology, sympathy, and empathy: The legal ramifications of admitting fault in U.S. public relations practice. Public Relations Review, 42(1), 176-183.

Nicolai, A.T., Schultz, A.-C., \& Göbel, M.(2011). Between sweet harmony and a clash of cultures: Does a joint academic-practitioner review reconcile rigor and relevance? The Journal of Applied Behavioral Science, 47(1), 53-75.

Pieczka, M. (2002). Public relations expertise deconstructed. Media, Culture \& Society, 24(3), 301-323.

Rasche, A., \& Behnam, M. (2009). As if it were relevant: A systems theoretical perspective on the relation between science and practice. Journal of Management Inquiry, 18(3), 243255.

Robbennolt, J.K. (2006). Apologies and settlement levers. Journal of Empirical Legal Studies, $3(2), 333-373$.

Rubin, J., \& Rubin, I.S. (2005). Qualitative interviewing: The art of hearing data (2nd edition). Thousand Oaks: Sage.

Seeger, M.W. (2006). Best practices in crisis communication: An expert panel process. Journal of Applied Communication Research, 34(3), 232-244. 
Shapiro, D.L., Kirkman, B.L., \& Courtney, H.G. (2007). Perceived causes and solutions of the translation problem in management research. Academy of Management Journal, 50(2), 249-266.

Sheldon, C.A., \& Sallot, L.M. (2009). Image repair in politics: Testing effects of communication strategy and performance history in a faux pas. Journal of Public Relations Research, 21(1), 25-50.

Sisco, H.F. (2012). Nonprofit in crisis: An examination of the applicability of Situational Crisis Communication Theory. Journal of Public Relations Research, 24(1), 1-17.

Sisco, H.F., Collins, E.L., \& Zoch, L.M. (2010). Through the looking glass: A decade of Red Cross crisis response and situational crisis communication theory. Public Relations Review, 36(1), 21-27.

Strauss, A., \& Corbin J. (1998). Basics of Qualitative Research: Techniques and Procedures for Developing Grounded Theory (2nd edition). Thousand Oaks: Sage.

Taylor, M. (2000). Cultural variance as a challenge to global public relations: A case study of the Coca-Cola scare in Europe. Public Relations Review, 26(3), 277-293.

Turk, J.V., Jin, Y., Stewart, S., Kim, J., \& Hipple, J.R. (2012). Examining the interplay of an organization's prior reputation, CEO's visibility, and immediate response to a crisis. Public Relations Review, 38(4), 574-583.

Ulmer, R.R. (2012). Increasing the impact of thought leadership in crisis communication. Management Communication Quarterly, 26(4), 523-542.

van der Meer, T.G.L.A., \& Verhoeven, J.W.M. (2014). Emotional crisis communication. Public Relations Review, 40(3), 526-536.

Venette, S.J. (2006). Special section introduction: Best practices in risk and crisis communication. Journal of Applied Communication Research, 34(3), 229-231. 
Wigley, S. (2011). Telling your own bad news: Eliot Spitzer and a test of the stealing thunder strategy. Public Relations Review, 37(1), 50-56.

\section{Appendix A. Topic List}

\section{Information About the Participants}

- Education

- Current function within the organization

- Length of experience as a communication professional

- Crises that the organization has been confronted with in the past (Question asked to internal communication managers only)

\section{Knowledge and Application of Public Relations Theory}

- Do you, as a PR professional, work mainly based on your gut feeling or based on theory? Why?

- Are you aware of crisis communication theory and research? If so, which theories and (how) do you put these into practice?

\section{How Crises Were Actually Handled in the Past}

- To what degree was your organization/the organization for which you consulted willing to take responsibility during actual crises?

- To what degree was your organization/the organization for which you consulted willing to self-disclose information, even when this information was detrimental to the organization? 
<smiles>C=CC1CC1</smiles> 